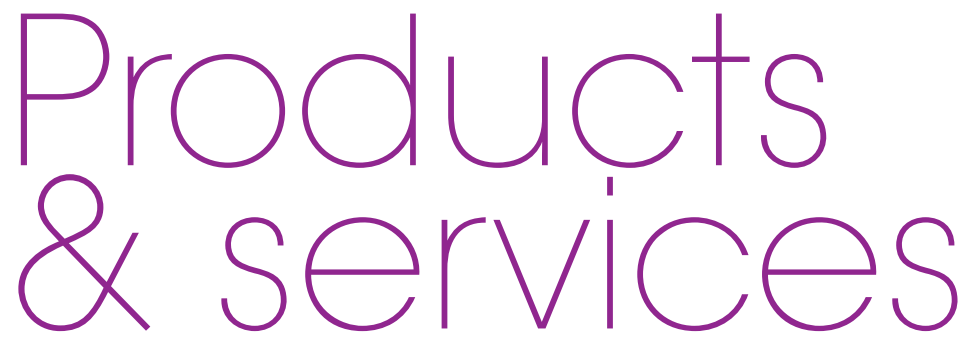

Product news is provided as a service to readers using text and images from
the manufacturer, supplier or distributor and does not imply endorsement by BDJ Team. Normal and prudent research should be exercised before

purchase or use of any product mentioned.

\section{DENTURE WEARERS USE ALL SORTS TO CLEAN THEIR TEETH}

\section{POLIGRIP}

A new study of more than 2,800 denture and partial denture wearers in six countries has found that more than ten different types of cleaning methods are used instead of specialist denture cleansers - including toothpaste, household bleach, dishwashing detergent and vinegar ${ }^{\top}$ - even though they often don't kill key bacterial and fungal microorganisms and some can damage denture materials. The findings were announced at a symposium at the IADR General Session in Cape Town, sponsored by GSK Consumer Healthcare.

The researchers found that most denture wearers use regular toothpaste to clean their dentures, followed by water, mouthwash and denture tablet cleansers either alone or in combination. More than 70\% said they had received or followed a recommendation from a dental health professional, while 30\% had not

However, in another study, the majority of dentists and dental hygienists said they most often recommend specialist denture cleansers to their patients.

While regular toothpaste is used by large numbers of denture wearers, research shows that it fails to effectively kill Candida albicans, ${ }^{2}$ a fungus which can cause denture stomatitis (thrush), as well as other bacteria that are associated with malodour and gum infections in denture wearers.

Toothpaste does not completely kill Candida, even after five minutes of treatment. Other methods, including soap, many mouthwashes and water also perform inadequately in these tests.

Until recently, denture care hygiene

has not been a research focus so

there is a lack of evidence-based recommendations. Consensus is limited; sharp differences exist between developed and emerging markets:4 and patient compliance is inconsistent.

Globally, 810 million people are aged 60 years or over; by 2050 they will number 2 billion. ${ }^{5}$ The incidence of denture wearing is high in this age group and the percentage of denture wearers is expected to rise. ${ }^{\circ}$ Research has shown that specialist denture cleansers are the optimal method for denture care hygiene - killing harmful oral microorganisms, ${ }^{2}$ while being gentle on denture material. ${ }^{3}$ Denture wearers who use specialist cleansers also report greater satisfaction with their cleaning regimen than other denture wearers

Poligrip Denture Cleansers from GSK have proven antibacterial and antifungal activity against a wide range of microorganisms, including Candida albicans. ${ }^{2}$ Poligrip also significantly reduces depth of abrasion on the denture compared with a regular toothpaste. Unlike toothpaste, Poligrip Denture Cleanser is gentle on denture materials. ${ }^{3}$

GSK data on file 2014, Multinational Diary study denture cleaning.

GSK data on file 2014, Antimicrobial testing denture cleanser vs household methods. GSK data on file 2014, Compatibility of different methods on denture materials.

4. GSK data on file 2014, Multinational dental recommendation study.

UNFPA and HelpAge International.

Steele J G. Treasure E, Pitts N B, Morris J, Bradnock G. Total tooth loss in the United Kingdom in 1998 and implications for the future. Br Dent J 2000: 189: $598-603$

\section{DESIGNED TO PREVENT CARIES IN CHILDREN}

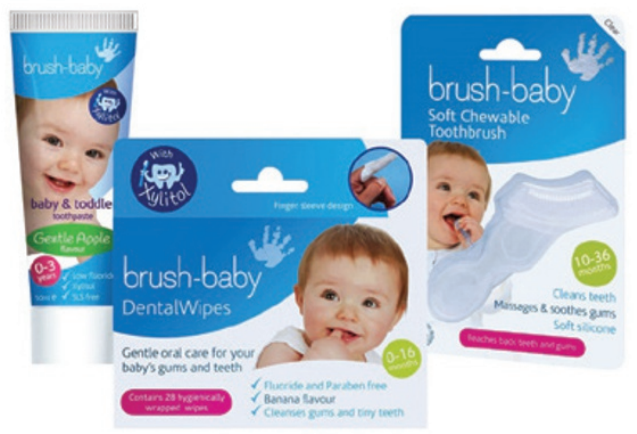

Infant dental care designer and

manufacturer Brush-Baby has a range of innovative products for babies, toddlers and children which will help parents protect their children's dentition from the tooth decay seen in Public Health England's recent survey [12\% of three-year-olds in England suffer from visible tooth decay].

Brush-Baby's Chewable Teether/ Toothbrush forms the basis of a threestep easy to follow oral care regime: step 1, 0-16 months, cleaning baby gums; step 2, 10 months - 3 years. teething and brushing; step 3, from 3 years, brushing and flossing.

Brush-Baby has ten products for babies, toddlers and infants from newborn to six years of age that are sold across 22 countries and stocked by UK retailers including Boots, Tesco, Sainsbury's, John Lewis, Waitrose and Mothercare.

Brush-Baby was started by a mum, Dominique Tillen who, frustrated at the lack of dental care products available for her daughter, decided to design her own.

For more information call 08455202229 or visit www.brushbaby.co.uk.

If you would like to promote your products or services direct to the dental industry in BDJ Team, just give Andy May a call on 02078434785 or drop an email toa.may@nature.com. 